\section{Research Article}

\section{Philipp Trein}

University of Lausanne and University of California, Berkeley

Martino Maggetti

University of Lausanne

\title{
Patterns of Policy Integration and Administrative Coordination Reforms: A Comparative Empirical Analysis
}

Philipp Trein is senior researcher at the University of Lausanne, Switzerland, and senior fellow in the Institute of European Studies at the University of California, Berkeley. His research focuses on comparative public policy, policy learning, federalism, and political economy. His book Healthy or Sick? Coevolution of Health Care and Public Health in a Comparative Perspective was published by Cambridge University Press in 2018. Information on his research is available at http://www. philipptrein.com.

E-mail: josefphilipp.trein@unil.ch Martino Maggetti is associate professor of political science in the Institute of Political Studies at the University of Lausanne, Switzerland. His research interests focus on regulatory governance and comparative public policy. Information on his research is available at http://www. maggetti.org.

E-mail: martino.maggetti@unil.ch
Public Administration Review, Vol. 80, Iss. 2, pp. 198-208. ( 2019 by The American Society for Public Administration. DOI: 10.1111/puar.13117.

\begin{abstract}
During the last two decades, scholars have pointed to a process of "denationalization," or the delegation of competencies away from the center of the nation-state-upward, downward, and sideward. At the same time, scholars have observed a transformation of the central state aimed at strengthening its steering capacity by means of integrating sectoral public policies and coordinating administrative units. Little systematic comparative evidence is available regarding this second phenomenon and its relationship with denationalization. The authors contribute to this line of research by presenting a comparative analysis of cross-sectoral reforms concerning public policies and public sector organizations, covering four policy fields in 13 countries, from 1980 to 2014. Using descriptive statistics and Bayesian change point estimation, this article shows that policy integration and administrative coordination reforms configure a powerful trend, which displays considerable variation across time, policy fields, and countries.
\end{abstract}

\section{Evidence for Practice}

- The emergence of new policy problems required increased integration and coordination of policies and administration. This growing demand for integration and coordination occurred during a period of denationalization —and partially as a response to it.

- Although many policy challenges entail interdependent decision-making that requires international cooperation and collaboration with subnational and private actors, our results suggest that the nation-state remains the focal point for the adjustment of public policies and administrative structures to specific policy challenges.

- The development of policy instruments that cut across sectors seems to provide momentum for administrative coordination reforms. Policy makers and civil servants should be aware that newly integrated policies are likely to generate demand for changes in the relationships among public sectors organizations, especially increased coordination between administrative units.

$\mathrm{T}$ The political institutions of nation-states, which constitute the cornerstone of democratic policy making, are considered durable and resilient (Mahoney and Rueschemeyer 2003; Pierson 2000). However, as much as any human artifact, they change over time. They typically do so through long-term processes of gradual transformation (Streeck and Thelen 2005) that can take many shapes and colors and, indeed, have been studied from different perspectives.

Over the last two decades or so, scholars have convincingly observed that the nation-state is being "hollowed out" (Rhodes 1994), "unraveled" (Hooghe and Marks 2003), and "disaggregated" (Slaughter 2004). In this vein, several pieces of research point to the pressures that come from above, from below, and from within, implying the relocation of political power beyond the boundaries of nation-states' central governments upward, downward, and sideward, ultimately resulting in the "denationalization" and "decentering" of policy making (Abbott and Snidal 2009; Hooghe and Marks 2001; Jordana and LeviFaur 2004; Piattoni 2010; Zürn 2000).

This broad phenomenon has also been tackled in the public administration and public policy research-for example, in the scholarship on New Public Management (NPM) reforms (Hood 1995; McLaughlin, Osborne, and Ferlie 2002). NPM entails the transformation of organizational structures and processes in public administration through the adoption and implementation of private sectororiented management principles and tools. These reforms typically involve the application of results-based management, competition between administrative units, and individual performance incentives (Pollitt and Bouckaert 2017). The creation of sector-specific agencies that enjoy a certain degree of autonomy from their political "principal" is another manifestation of this reform agenda (Maggetti and Verhoest 2014). 
Nevertheless, governments have engaged in reforms that have progressively rearranged the boundaries that demarcate the goals and instruments of specific policy programs and the tasks of public sector organizations. These post-NPM reforms have been labeled "joined-up government" (Bogdanor 2005) and "whole-ofgovernment" (Christensen and Lægreid 2007c), among other terms (Tosun and Lang 2017). A key goal of these post-NPM reforms is to counteract the fragmentation created by NPM reforms by adopting a more holistic approach — that is, to cut across policy sectors (Bouckaert, Peters, and Verhoest 2010; Christensen and Lægreid 2007b, 2007c; Egeberg and Trondal 2016)—-thereby ultimately reinforcing the central government (Dahlström, Peters, and Pierre 2011).

These reorganizations entail "policy integration," which is intended to bundle existing policy goals and instruments across policy sectors, or to create them anew, so as to increase the effectiveness and legitimacy of policy programs (Hou and Brewer 2010; Schaffrin, Sewerin, and Seubert 2015), for instance, in environmental policy (Jordan and Lenschow 2010). On the other hand, such reforms also require "administrative coordination" aimed at strengthening the collaboration between public sector organizations (Reiter and Klenk 2018, 18) to tame the downsides of NPM reforms (Richards and Kavanagh 2000). Although they respond to a similar problem, the policy-and organization-related dimensions are usually treated separately in the research, which is largely based on in-depth case studies of these types of reforms (Trein, Meyer, and Maggetti 2019).

To make sense of this apparently paradoxical cooccurrence of denationalization and recentering, we embark on a comparative empirical analysis of reforms aimed at strengthening the steering capacity of the state. Beyond the specific context related to the analysis of post-NPM reforms, this study contributes to the wider literature on the transformation of the nation-state. We pose three research questions that aim to link the transformation of the nation-state with NPM and cross-sectoral policy and organizational reforms: (1) Does the process of recentering public policies and governmental structures take place sequentially as a reaction to the decentering and fragmentation of authority, or is it a parallel, intertwined development? (2) What is the magnitude of this phenomenon at the macro level, and in what manner did it unfold? (3) Can we identify systematic trajectories and variations with respect to policy-specific and country-specific factors, and if so, how do they unfold?

To tackle these questions, this article presents the results of a comparative empirical analysis of reforms in 13 countries across four policy fields. The selected countries are Australia, Austria, Belgium, Canada, France, Germany, Italy, Netherlands, New Zealand, Sweden, Switzerland, the United Kingdom, and the United States. We focus on environmental, migration, public health, and unemployment policy over the time period from 1980 to 2014 .

Results show that the overall magnitude of reforms is remarkable: a powerful recentering trend took place at roughly the same time as the processes of denationalization. What is more, distinguishing between policy integration and administrative coordination provides analytical leverage, as the two reform trajectories are related but do not overlap. Finally, field- and country-specific factors shape the pace of reforms, whose highest frequency tends to occur in environmental policy and in countries with a centralized political system and an Anglo-Saxon administrative tradition.

\section{Toward a Comparative Empirical Analysis of Post-NPM Reforms}

In this article, we adopt a research strategy geared toward description and interpretation as fundamental building blocks of scientific understanding, which is particularly appropriate when the goal is to map a relatively uncharted territory (Gerring 2012). In line with this approach, we aim to answer questions asking to what and in what manner, namely, by accounting for the varying empirical manifestations of the phenomenon of interest and investigating the associations occurring between multidimensional components of this phenomenon. Therefore, our analysis is guided by broad theoretical expectations (but not specific hypotheses) about general regularities and variations in our observations (Gerring 2012). In line with our exploratory approach, these expectations are sometimes directional and sometimes fully openended.

\section{Policy versus Administrative Dimension}

The first element that guides our analysis is the distinction between two dimensions: policy reforms and organizational reforms. Our approach builds on previous comparative studies of policy and administrative integration and/or coordination. Prior research has employed scales of coordination (Bouckaert, Peters, and Verhoest 2010, 16; Braun 2008, 230-1; Jordan and Schout 2006; Metcalfe 1994). Instead, we use a dichotomous conceptualization that incorporates a distinction in kind (Sartori 1970) between the policy dimension and the administrative/organizational dimension of cross-sectoral reforms (Tosun and Lang 2017; Trein, Meyer, and Maggetti 2019). This strategy allows us to analyze the sequencing of policy and organizational reforms cutting across policy sectors as an open empirical question. Specifically, we refer to policy integration and administrative coordination, which we define as follows:

Policy integration denotes the policy dimension of reforms aimed at achieving crosscutting policy goals - that is, policy instruments spanning policy sectors or subsystems (we use the two terms as synonyms) in a larger policy field (Candel and Biesbroek 2016, 211-2; Jochim and May 2010). Decision makers usually enact policy integration reforms to deal with policy challenges needing comprehensive solutions that are beyond the scope of existing policy configurations (Peters 2015, 4). Empirical instances of policy integration are legislative changes that connect or combine existing laws or new political strategies that embody future visions or plans that explicitly link various policy fields or subsystems (Trein 2017b).

Administrative coordination pertains to the administrative and organizational dimension of cross-sectoral policy reform. It concerns reforms that change the relationships between public sector organizations (Bouckaert, Peters, and Verhoest 2010, 36-40), with the goal of improving coordination (Christensen and Lægreid 2007c, 1059-60). Distinguishing between the policy and administrative dimensions is important because public sector organizations tend to be particularly resistant to change (Buchanan and Badham 2008; Pierson 1998, 552-3), thus reform events are potentially rarer than for policy integration. Administrative coordination reforms entail 
creating procedures to avoid negative spillovers and improving cooperation between administrative organizations. Examples are impact assessments, co-signing of legislative proposals, the establishment of transversal public sector agencies or units in charge of coordination (Bouckaert, Peters, and Verhoest 2010; Perri 62004 , $10)$, or even the merger of administrative organizations or ministries (Perri 6 2004, 108; Perri 6 et al. 2002, 29-34).

\section{Complexity of Policy Problems}

The second element that guides our analysis is the assumption that patterns of policy integration and administrative coordination reforms vary according to the complexity of the policy problem (Christensen, Lægreid, and Lægreid 2019; Head and Alford 2015; Peters 2017, 392), which, in turn, determines the demand for coordination (Peters and Savoie 1996). We focus on two dimensions of complexity. On the one hand, we expect that the intrinsic technical complexity of the policy field shapes the dynamics of policy integration and administrative coordination. We assume that "technical complexity is high when a policy problem requires the understanding of a specialist or expert, a professional appraisal more than a normative judgment" (Gormley 1983, 89-90). Although technical decisions can also be based on normative criteria, and vice versa, it is fruitful for comparative policy analysis to distinguish between predominantly technical policies, for which the use of knowledge and expertise is prominent in the policy process, and less technical ones, which mostly require other political resources (Gormley 1983, 90; see also Eshbaugh-Soha 2006).

On the other hand, we expect that reform trajectories vary according to the scope of policy integration and administrative coordination. Their scope varies depending on whether dealing with the policy problem requires the incorporation of policy instruments and organizational structures (Meyer and Rowan 1977) from a small number of relatively close sectors within a single policy field, or alternatively, it implies bringing together a multitude of policy instruments and organizational structures from sectors that span across policy fields (Jochim and May 2010). Here, we discuss the pertinence of these distinctions for our argument.

The policy fields and the related problems requiring integration and coordination that we chose for this analysis vary according to their technical complexity and the scope of integration and coordination (see table 1).

Environmental policy is a case of technical complexity, as it involves the use of technical expertise on a wide range of environmental issues (Oreskes and Conway 2010). Furthermore, policy integration and administrative coordination concern incorporating environmental matters into other policy fields, or unhinging competencies from different policy fields (energy, competition, transportation, housing, etc.) to integrate them into a coherent environmental policy field. Examples of policy integration are

Table 1 Variation of Integration and Coordination Complexity across Policy Fields

\begin{tabular}{llll}
\hline & & \multicolumn{2}{l}{ Scope of Integration and Coordination } \\
\hline & Within Policy Field & Across Policy Fields \\
\hline Technical & Lower & Employment & Migration \\
& Higher & Health & Environment \\
\hline
\end{tabular}

framework laws and strategies focusing on environmental, climate, or sustainability issues; an instance of administrative coordination is the establishment of a national ministry for environmental policy or coordinating council for administrative policy implementation. In addition to touching on multiple policy sectors, environmental policy spans the local to the global level (Adelle and Russel 2013; Jordan and Lenschow 2010).

Health policy is a technically complex field that involves medical and public health research (Oreskes and Conway 2010). However, policy integration and administrative coordination remain largely within the wider policy field and focus on the link between health care and public health or even more specific measures, such as integrated care (Trein 2017a, 2018). In this article, we focus on policy integration reforms that integrate preventative and curative aspects of health policy, for example, strategies targeting noncommunicable diseases or the integration of screening measures into health care plans. Administrative coordination reforms are changes geared toward strengthening the coordination between the public sector organizations in charge of health care (e.g., public hospitals) and those in charge of public health (the ministry or department of health).

Migration policy typically relies less extensively on expert knowledge than environmental and health policy, as it is treated as comparatively less technically complex. At the same time, policy integration and administrative coordination span other policy fields, such as border management, housing policy, education, and employment (Entzinger and Biezeveld 2003; Scholten, Collett, and Petrovic 2017). In this case, examples of policy integration reform are legislative changes aimed at promoting encompassing strategies related to immigrant inclusion, which could involve social housing and language training; administrative coordination reforms are measures aimed at coordinating administrative units from different ministries, which share the responsibility for the inclusion of immigrants.

Unemployment policy is a very important but quite well-delimitated issue that does not percolate systematically into other policy fields. What is more, it is also a case of relatively limited technical complexity, as "standard models" for dealing with the problem exist. We focus on reforms integrating and coordinating employment promotion services with cash transfers. One example related to policy integration concerns reforms that make the receipt of cash benefits conditional on participation in labor market activation measures. Instances of administrative coordination reforms are measures that stimulate cooperation between the public sector organizations responsible for benefit payment and those in charge of labor market activation (Aurich-Beerheide et al. 2015; Champion and Bonoli 2011).

To ensure comparability among these policy fields, we examine policy goals (environmental protection, improvement of public health, immigrant integration, and reduction of unemployment) (Howlett and Cashore 2009, 39). We compare reforms that aim to achieve these goals through (1) an adjustment of substantive policy instruments and (2) a reconfiguration of the relations between public sector organizations with respect to the sectoral elements that are relevant to integration in the policy field. This strategy allows 
us to examine policy field-specific problems using a comparative approach.

\section{Contextual Factors \\ Time and Sequence}

The third element guiding our analysis concerns the timing of reforms. We expect that post-NPM reforms should start appearing during the 1980s and 1990s (Christensen, Lie, and Lægreid 2007, 18), with a peak after 2000 (Christensen and Lægreid 2007a). We selected 1980 as the starting point because the trend toward NPM reforms conventionally began after this year (Hood 1991; McLaughlin, Osborne, and Ferlie 2002). We also expect that the policy integration and administrative coordination reforms are spread across the countries in our sample but that they appear in Anglo-Saxon countries first and later in other European countries (Christensen and Lægreid 2007c). Furthermore, there could be a sequence of policy- and organization-related reforms, yet we do not have a precise expectation of the shape of this relationship.

Administrative Traditions. The fourth element focuses on the variance among countries. In this regard, we expect differences among countries according to their administrative traditions and the degree of government centralization. Concerning administrative traditions, we formulate an open expectation, namely, that there are differences in reform patterns among countries with Anglo-Saxon, Germanic, Napoleonic, and Scandinavian traditions (Painter and Peters 2010). Furthermore, we expect to find less national-level policy integration and administrative coordination reforms in decentralized states because of the autonomy of subnational and regional government regarding policy making and implementation (Pollitt and Bouckaert 2017, 51-5). The countries that we include in our analysis-Australia, Austria, Belgium, Canada, France, Germany, Italy, the Netherlands, New Zealand, Sweden, Switzerland, the United Kingdom, and the United States — vary across these two dimensions.

Supranational Authority (European Union). The fifth element that guides our analysis concerns the European Union (EU). In this instance, we expect that there are differences between EU members and non-EU members concerning policy integration and administrative coordination reforms, because of the role played by the emerging European administrative space as a platform for cooperation (Egeberg and Trondal 2016; Levi-Faur 2011). This expectation complements the first one, as it implies that the intensity of such reforms should be higher in EU member states but that they come at a later point in time compared with non-EU members. Again, there is variance according to this dimension in the countries included in our empirical analysis.

\section{Data Collection and Analytical Strategy}

To operationalize our conceptual framework, we created a new multilevel time-series data set of reform events that records events of policy change over time. We assembled information on policy integration and administrative coordination reform instances in the four policy fields and 13 countries as we expect variance according to the reasons mentioned earlier. Our analysis focuses on reform events producing a statutory change in policy integration and administrative coordination (Sarapuu et al. 2014, 263-4), about which information is reliably available through desk research, and we could straightforwardly contact experts for support. This approach allows us to capture above all formal changes through policy making, but we purposely do not measure changes in implementation practices or the entire policy paradigm (Hall 1993). The data set includes information on reforms for the period 1980 to 2014. A detailed discussion of the operationalization process and the data collection strategy can be found in the Supporting Information online.

To measure policy integration and administrative coordination reforms, we collected a data set of reform events, similar to policy diffusion and conflict research (Prorok and Huth 2015; Maggetti and Gilardi 2016). The data set measures reforms using two binary variables $(0 / 1)$ - one for policy integration and the other for administrative coordination-per policy field in a country and year, which results in a data set with 1,820 observations on the dependent variable.

To analyze our data, we first present descriptive results for policy integration and administrative coordination reform events, over time, on three levels: (1) overall reforms, (2) reforms per policy field, and (3) reforms per country. Next, we use Bayesian change point analysis (Carlin, Gelfand, and Smith 1992) to determine objectively whether there is a structural break in the reform frequency overall, at the policy field level, and across countries (Carlin, Gelfand, and Smith 1992; Leemann 2015, 598).

We estimate change point models for policy integration and administrative reforms overall, per policy field, and per country. We fit models that test for one change point, as we want to compare reform sequences for types of reforms (policy integration or administrative coordination), policy fields, and countries. We are interested in comparing sequences across reform types, policy fields, and countries. If it is not possible to credibly estimate a model with one change point, we conclude that that there is no single structural change but rather a more complex distribution of reforms over time. ${ }^{1}$ More information on the models can be found in the Supporting Information.

\section{Results of the Empirical Analysis Reforms over Time}

We start the presentation of the results by considering the overall frequency of policy integration and administrative coordination reforms over time. A simple description of the data shows that the two types of reform are slightly correlated (correlation coefficient: 0.16 ), but the results also reveal differences between them (figure 1). ${ }^{2}$ The dynamics of the two reform types are similar in that after the onset of reforms during the 1980s, the number of reforms increases steeply, reaches a peak in the mid-2000s, and declines afterward.

The two types of reforms coevolve differently, as the data suggest a much higher frequency of policy integration reforms than administrative coordination reforms. There is a steeper increase in policy integration reforms frequency compared with administrative coordination reforms; notably, administrative coordination reforms peak around 2000 and become less frequent afterward. Policy integration reforms occur more often and reach the highest point a bit later than administrative coordination reforms. 
There are interesting similarities and differences among the policy fields concerning the frequency of policy integration and administrative coordination reforms. The four policy fieldsenvironment, migration, public health, and unemployment-are similar insofar as there are more policy integration reforms than administrative coordination reforms. Furthermore, we observe a tendency toward more reforms in the second half of the time series (after 1997) in all policy fields (figure 2). The correlations of policy integration reforms and administrative coordination reforms also vary among the policy fields. The co-occurrence of the two types of reforms is highest in the field of migration policy (correlation: 0.22) and lowest with respect to public health policy (correlation: 0.08).

On the other hand, there are differences among the four policy fields concerning policy integration and administrative coordination reform activities. Regarding environmental policy, we witness greater overall reform intensity than in the other three policy fields and more administrative coordination reforms than policy integration reforms, notably before the early 1990s. Migration and public health show many more policy integration reforms than

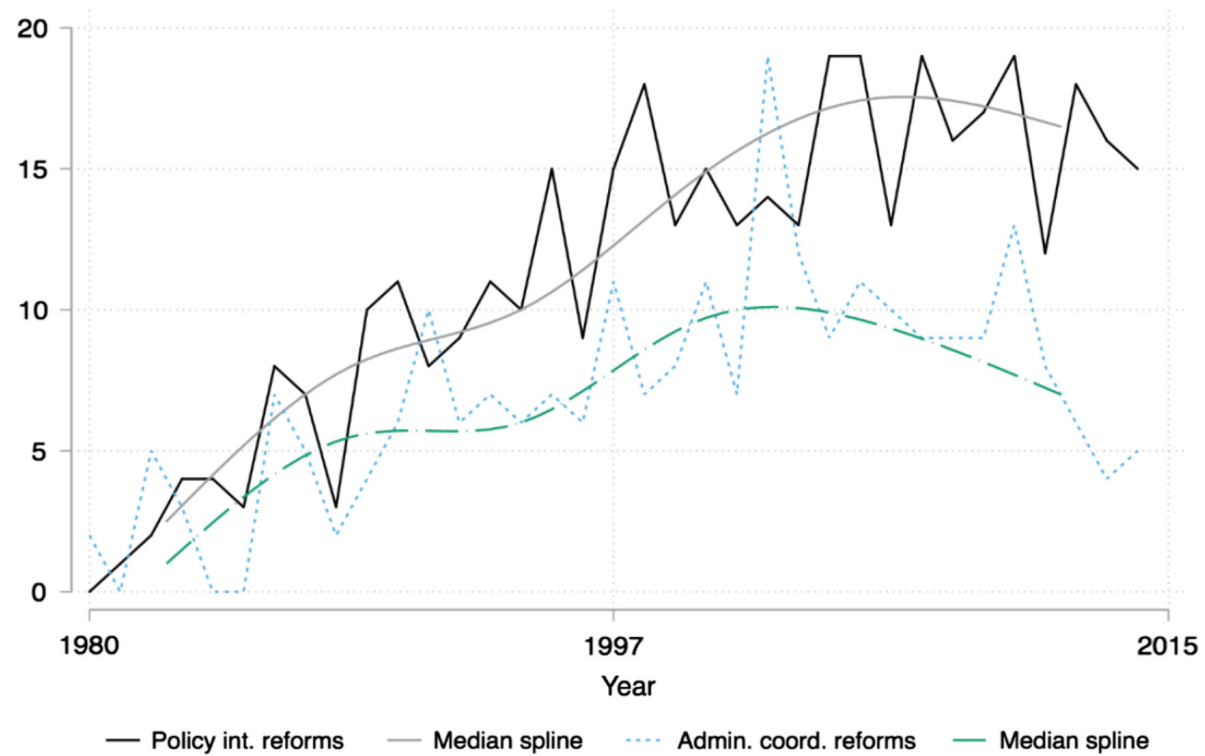

Figure 1 Policy Integration and Administrative Reforms over Time (Overall)

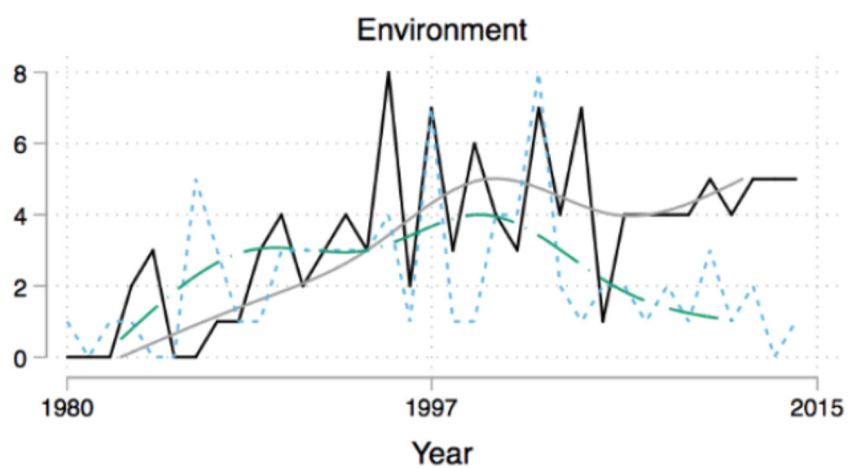

Unemployment

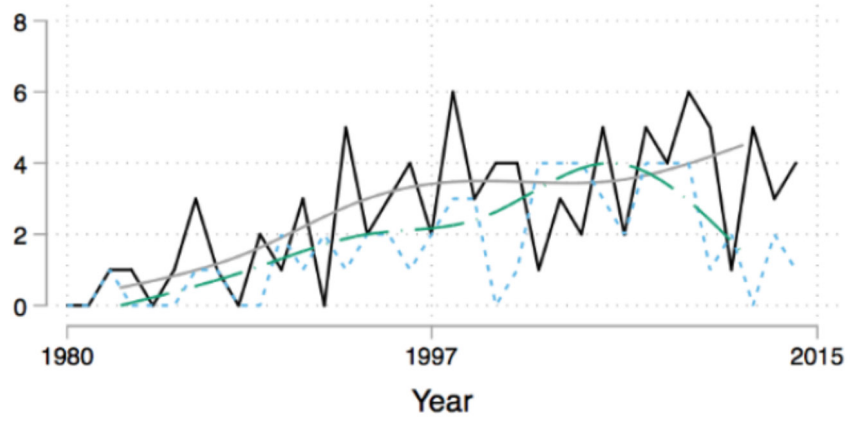

Policy int. reforms

Median spline

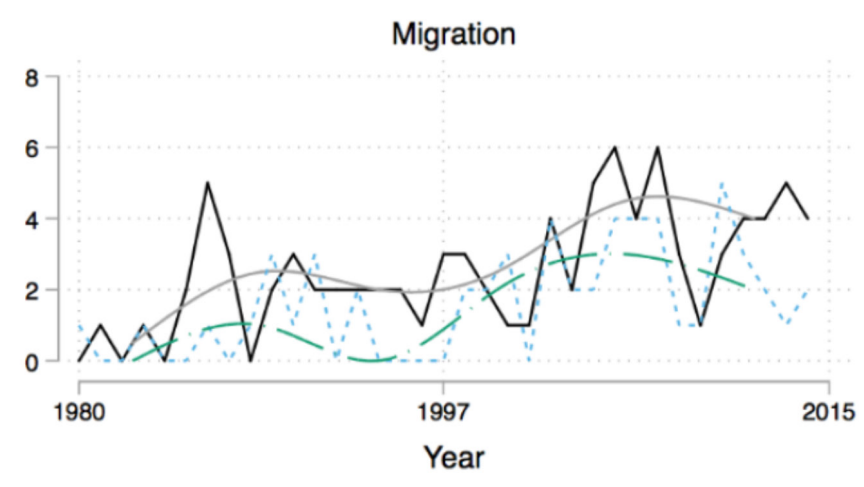

Public Health

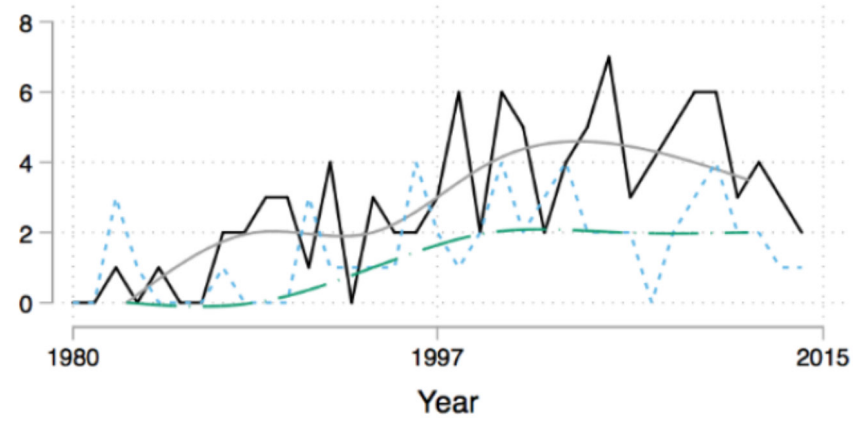

Admin. coord. reforms $\quad \longrightarrow$ Median spline

Figure 2 Administrative Coordination and Policy Integration Reforms in Different Policy Fields

202 Public Administration Review • March|April 2020 
administrative coordination reforms compared with environmental and unemployment policy. On the other hand, reform activity concerning unemployment is different, as both policy integration reforms and administrative coordination reforms increase in parallel but then evolve differently_policy integration reforms retain a similar frequency, whereas administrative coordination reforms reach a high point that goes beyond the frequency of policy integration reforms in the mid-2000s and decrease significantly after that (figure 2).

\section{Variance among Countries}

The next part of the descriptive analysis focuses on differences among countries while also accounting for reform types and policy fields. To effectively map the magnitude of these reforms, we standardize the reform count around the mean by two standard deviations per country and policy field, which ensures comparability of the data (Gelman 2008; King 1986). First, we look at the overall patterns of reform (figure 3). The results allow us to delineate four country groups of policy integration and administrative coordination reforms; some countries belong clearly to one group, whereas others are more in between.

The first group comprises countries with a high frequency of policy integration and administrative coordination reforms (upper-right quadrant, figure 4), namely, the United Kingdom and Sweden. The Netherlands scores lower on the administrative coordination dimension but remains high on the policy integration score. Australia and New Zealand are formally in this group but remain close to the mean of the overall reform activity. The second group includes Austria and Germany, which have many policy integration reforms but few administrative coordination reforms (upper-left quadrant, figure 3). The third group includes countries with few policy integration and few administrative coordination reforms (lower-left quadrant, figure 3), corresponding to Canada and the United States. Belgium remains close to the mean of administrative coordination reforms but clearly belongs to the group with few policy integration reforms. The fourth group consists of countries that have experienced few policy integration reforms and many administrative coordination reforms (lower-right quadrant, figure 3). The most evident members of this group are France and Italy. Switzerland is situated at the margins of the group close to the mean of few policy integration reforms but clearly is part of the set of countries with few administrative coordination reforms.

Now, we turn to the comparison of policy fields. In environmental policy, countries have undergone more policy integration and administrative coordination reforms compared with other policy fields. Five countries are in the group with many policy integration and administrative coordination reforms in this field (upper-right quadrant, upper-left graph, figure 4). Particularly, Austria, the Netherlands, Sweden, and Switzerland are fully in this group. The United Kingdom has many administrative coordination reforms, but it is just located slightly above the mean for policy integration reforms.

The second group of countries are those with many policy integration but few administrative coordination reforms in environmental policy (upper-left quadrant, upper-left graph, figure 4). The countries in this group are France, New Zealand, and the United States. There is only one country with few policy integration and few public administration reforms, Canada, but it is located close to the mean of policy integration and administrative coordination reforms (lower-left quadrant, upper-left graph, figure 4). Countries with few policy integration reforms but many administrative coordination reforms, in environmental policy, are Australia, Belgium, Germany, and Italy (lower-right quadrant, upper-left graph, figure 4).

Concerning migration policy, there is a different picture, as most countries belong to the group with few policy integration and few administrative coordination reforms (lower-left quadrant, upper-right graph, figure 4). These countries are Austria, Belgium, Canada, Germany, Switzerland, and the United States. Germany, however, is close to the mean of policy integration and

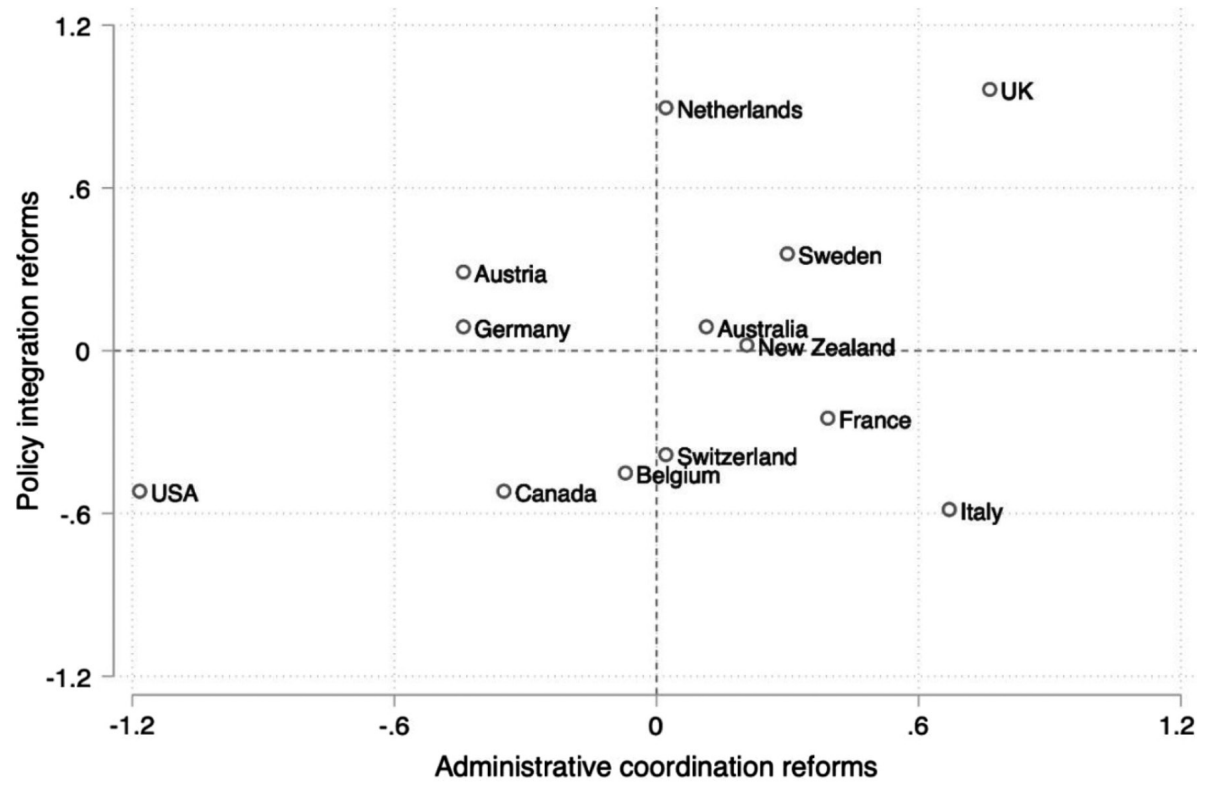

Figure 3 Overall Reforms of Policy Integration and Administrative Coordination 

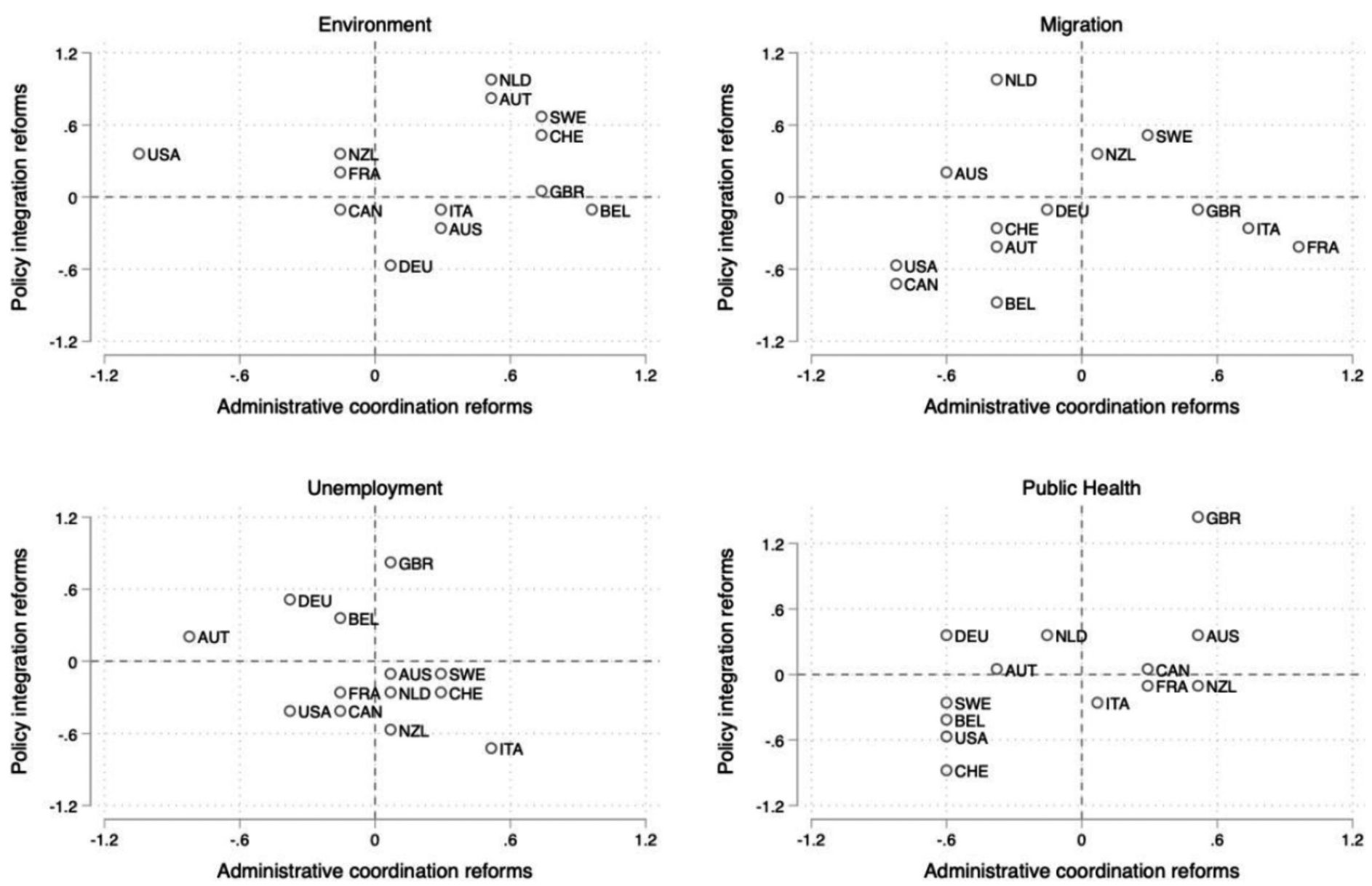

Figure 4 Policy Integration and Administrative Coordination Reforms in Countries and Policy Fields

administrative coordination reforms. The only two countries with many policy integration and administrative coordination reforms in the field of migration policy are New Zealand and Sweden (upperright quadrant, upper-right graph, figure 4). There are two countries with many policy integration but few administrative coordination reforms: Australia and the Netherlands (upper-left quadrant, upperright graph, figure 4). Three countries are in the group with few policy integration but many administrative coordination reforms, namely, France, Italy, and the United Kingdom (lower-right quadrant, upper-right graph, figure 4).

In the field of unemployment policy, the United Kingdom is the only country with many policy integration and administrative coordination reforms, although it is close to the mean of the administrative coordination reform measure (upper-right quadrant, lower-left graph, figure 4). Austria, Belgium, and Germany experienced many policy integration reforms but few administrative coordination reforms (upper-left quadrant, lower-left graph, figure 4). The rest of the countries cluster together below the mean of policy integration reforms and relatively close to the mean of administrative coordination reforms. On the one hand, Canada, France, and the United States are in the group with few policy integration and administrative coordination reforms (lower-right quadrant, lower-left graph, figure 4). On the other, Austria, Italy, the Netherlands, New Zealand, Sweden, and Switzerland belong to the group with few policy integration but many administrative coordination reforms (lower-right quadrant, lower-left graph, figure 4). Italy is the only country that is fully in the group, whereas the other countries are located closer to the mean.

Finally, there is again a different picture regarding public health. Canada, Australia, and the United Kingdom display many policy integration and many administrative coordination reforms, but the countries within this group differ in that the United Kingdom is an outlier, whereas Canada is close to the mean of policy integration reforms (upper-right quadrant, lower-right graph, figure 4). Austria, Germany, and the Netherlands have experienced many policy integration and few administrative coordination reforms (upper-left quadrant, lower-right graph, figure 4), although Austria is close to the mean of policy integration reforms. Belgium, Sweden, Switzerland, and the United States have had few policy integration and many administrative coordination reforms (upper-left quadrant, lower-right graph, figure 4). France, Italy, and New Zealand are in the group with few policy integration and many administrative coordination reforms (lower-left quadrant, lower-right graph, figure 4).

\section{Change Point Analysis}

We turn now to the second part of the analysis, which reports the results of the Bayesian change point estimates. The change point analysis returns an estimated change point in 1988 for policy integration and in 1989 for administrative coordination reforms. The change point estimates are credible in a three-year (policy integration) and five-year (administrative coordination) interval, which is quite precise (see table S3 in the Supporting Information, 
part 1). ${ }^{3}$ These results indicate that there is a (quasi)parallel development of policy integration and administrative coordination reforms because both types of reform increase in frequency around the same year relative to the previous period $(1988,1989)$.

Concerning the differences among policy fields, the results of the change point analysis offer more insight into the sequencing of policy integration and administrative coordination reforms. We estimate one model for each policy field. Overall, the change points for policy integration and administrative coordination reforms are close to one another, which underlines the parallel trajectory of reforms concerning the cross-sectoral policy dimension as well as administrative-focused reforms that change the relations between organizational units (table 2; see also table $\$ 4$ ). ${ }^{4}$

Environmental policy is the only field in which the sequence from few to many administrative coordination reforms changed prior to the reforms concerning policy integration. On the other hand, in the fields of migration and public health, the change from few to many policy integration reforms occurred prior to the change in administrative coordination reform. Concerning unemployment, the difference in change points is too marginal to be discernible, that is, the administrative coordination and policy integration reform sequences changed in parallel to each other (table 2; see also table S4).

The change point analysis of reform activities in different countries returns even more interesting findings. We estimated one model per country (table 3 ; see also table S5)..$^{5}$ The results of the analysis reveal remarkable similarities and differences among countries concerning the dynamics of policy integration and administrative integration. The most striking similarity is that in most countries, the change point for policy integration reforms precedes the change point for administrative coordination reforms. Exceptions to this finding are Austria, New Zealand, and Switzerland, where the change point for administrative coordination reforms is located before the one concerning policy integration reforms; Belgium and Italy are also interesting, as in these two countries, the change points for the two reform types are very close to one another. Nevertheless, we need to interpret these results carefully because the change point estimates for administrative coordination reforms have large credibility intervals for Austria and New Zealand (table 3; see also table S5). Furthermore, in Germany and the Netherlands, the change points for administrative coordination reforms have different interpretations; they are different from the other countries since the first period ( $\mathrm{t} 1$ ) contains more administrative coordination reforms than the second period $(\mathrm{t} 2)$, unlike the other countries and periods where the mean reform rate of the first period (prior to the change point) is always lower than the one after the change point.

\section{Theoretical Implications}

Our analysis makes five broad theoretical contributions that are specifically relevant for public administration and public policy scholarship but also provide insights into political research in a wider sense.

First, the overall magnitude of policy integration and administrative coordination reforms is worthy of attention. The dynamics of recentering are pervasive across sectors and countries, indicating a powerful reform trend. Our results suggest that these reforms emerged almost in parallel with the onset of NPM reforms. Thus, post-NPM reforms (Pollitt and Bouckaert 2017, 217) are part of a larger wave of policy change that recenters governance in the nation-state (Christensen, Lie, and Lægreid 2007). These reforms are not only a reaction to some of the problems created by NPM reforms but also coincide with policy changes aiming to reorganize political coordination structures to deal with new policy challenges (Christensen and Lægreid 2007a, 11). Therefore, they aim to deal with the particular problems induced by NPM while also following from the processes of denationalization upward, downward, and sideward (Zürn 2000), suggesting that these phenomena are more complex than is usually thought. Our findings imply that denationalization and recentering are actually intertwined and should be considered as two sides of the same coin, whereby the devolution of powers from the central state creates the need and the momentum for reorganizing the relationships between policy sectors and among public sector organizations (see Egeberg and Trondal 2018).

Second, our results indicate that it makes sense to distinguish between a policy and an organizational dimension of integration and coordination. Indeed, it appears that the trajectories of policy integration and administrative coordination reforms are related and overlap partially, but they are not perfectly correlated; they also exhibit some discrepancies with concerning their frequency and timing. It is important to note that in most cases, the change point for policy integration reforms precedes the change point for administrative coordination reforms (with exception of the relatively new issue of environmental protection), implying that policy change tends to shape organizational reforms and not the reverse (Christensen and Lægreid 2007c). In other words, policy integration reforms tend to create a demand for more administrative coordination, resulting in the reassertion of the central government (Christensen, Lie, and Lægreid 2007; Dahlström, Peters, and Pierre 2011).

Third, our findings point to variance among policy fields in line with the complexity of reforms, namely their technical complexity and scope. We witness more overall reform intensity in environmental policy-a technically complex, wide-ranging field - than in the other areas, and specifically more administrative coordination reforms in the early years, a result that may stem from the fact that this is a more recent policy field compared with the others. These results suggest that policy makers pursue integration coordination reforms especially in policy fields presenting complex

Table 2 Change Point Analysis per Policy Field

\begin{tabular}{|c|c|c|c|c|}
\hline Change point & Environment & Migration & Unemployment & Public Health \\
\hline Policy integration & 1989 & (1997) & 1992 & (1989) \\
\hline Administrative coordination & 1986 & (1999) & (1991) & (1992) \\
\hline Sequence of structural changes & $A C \rightarrow P I$ & $P l \rightarrow A C$ & $A C / P I$ & $P I \rightarrow A C$ \\
\hline
\end{tabular}




\begin{tabular}{lccl}
\hline Country & Policy Integration & $\begin{array}{c}\text { Administrative } \\
\text { Coordination }\end{array}$ & \multicolumn{1}{c}{ Sequence } \\
\hline Australia & 1984 & 1998 & $P l \rightarrow A C$ \\
Austria & 1996 & $(1993)$ & $A C \rightarrow P I$ \\
Belgium & 1990 & 1990 & $\mathrm{AC} / \mathrm{PI}$ \\
Canada & 1988 & 1991 & $P l \rightarrow A C$ \\
France & 1997 & 2001 & $P l \rightarrow A C$ \\
Germany & 2000 & $(2003)$ & $P l \rightarrow A C(A C \rightarrow P I)$ \\
Italy & 1986 & $(1985)$ & $A C / P I$ \\
Netherlands & 1996 & $(2006)$ & $P l \rightarrow A C(A C \rightarrow P l)$ \\
New Zealand & 1998 & $(1990)$ & $A C \rightarrow P I$ \\
Sweden & 1992 & 1996 & $P l \rightarrow A C$ \\
Switzerland & 1991 & 1986 & $A C \rightarrow P I$ \\
United Kingdom & 1985 & 1993 & $P l \rightarrow A C$ \\
United States & 1990 & $(2001)$ & $P l \rightarrow A C$ \\
\hline
\end{tabular}

policy problems (Christensen, Lægreid, and Lægreid 2019). The concentrated or dispersed distribution of reform targets and their strength or weakness in terms of resources and capacity resulting from differences in complexity may help explain these variations; further research, however, is required to explore the impact of these factors.

Fourth, with respect to variations across countries, the main findings suggest that reform activity is more intense in countries within the Anglo-Saxon administrative tradition. These countries were not only among the first to create post-NPM reforms (Christensen and Lægreid 2007a, 11) but are also forerunners in policy integration reforms, especially Australia, Canada and the United Kingdom. Furthermore, our results indicate that the Netherlands, the United Kingdom, and Sweden are in the group with a high intensity of post-NPM reforms (figure 4). This is finding resonates with the literature, which argues that "measured in terms of management tool use, Sweden, the United Kingdom and the Netherlands would seem to be the countries most committed to NPM reforms" (Jeannot and Bezes 2016, 225). Our results suggest also that there are some differences among countries belonging to the Germanic and Napoleonic administrative traditions (Painter and Peters 2010). In Germany and Austria, policy integration reforms outweigh administrative coordination reforms, whereas this relationship is inverse in France and Italy. Countries with a Napoleonic state tradition, notably France, have a centralized and politicized bureaucracy (Dahlström, Peters, and Pierre 2011,13) that functions as a "general purpose elite for the state" (Ongaro 2009, 254). Therefore, the predominance of administrative coordination over policy integration reforms makes sense in these countries. Our results imply that the vertical centralization of the state structure (Pollitt and Bouckaert 2017, 54) plays a role regarding the intensity of post-NPM as well as policy integration and administrative coordination reforms in general. For example, the German government conducted administrative reforms at the lower level of government (Andrews et al. 2016, 277). The differences within the Anglo-Saxon group of countries-notably, between the centralized United Kingdom, on the one hand, and decentralized Canada and the United States, on the other, emphasize this point.
Fifth, the timing and sequencing of reforms varies considerably among countries. This also provides evidence concerning differences between administrative traditions. Notably, AngloSaxon countries have early change points for reform activity, especially concerning policy integration reforms, as illustrated by Australia, Canada, and the United Kingdom but not the United States. Conversely, other countries have early change points for policy integration or administrative coordination reforms, notably, Italy and Switzerland. These findings underline the importance of country-specific effects of timing (Pierson 2000) and reform intensity.

\section{Conclusions}

This article provided systematic comparative evidence on the reassertion of the center of the nation-state by means of integrating sectoral public policies and by coordinating administrative units. We presented a comparative analysis of cross-sectoral policy and administrative reforms. Our descriptive statistics and Bayesian change point estimations indicate that policy integration and administrative coordination reforms configure a powerful trend. These reforms took place roughly at the same time of the processes of denationalization upward, downward, and sideward (Zürn 2000)—and, more specifically, following the spread of post-NPM reforms (Christensen and Lægreid 2007c), suggesting that denationalization and recentering are actually intertwined phenomena. This overall trend displays considerable variation across time, policy fields, and countries. In particular, the highest frequency of reform is found in environmental policy and in unitary Anglo-Saxon countries. With a broad comparative perspective focusing on the cross-national level, our study complements and extends research on municipal collaboration (Klok et al. 2018; Song, Park, and Jung 2018) and environmental policy integration at the local level (Krause et al. 2019).

A systematic discussion of the determinants of these variations is beyond of the scope of this article. Future research needs to explore the interplay of various explanatory factors, such as administrative traditions, the degree of centralization of the state, and the timing of reform events. What is more, future scholarship should explore the role of additional variables such as partisan ideology (Jain and Sarkar 2018), as well as the extent to which intense policy integration and administrative coordination reforms will eventually result in paradigmatic changes (Hall 1993) with regard to crosssectoral governance. Finally, future research should study the implementation phase and find out whether policy integration and administrative coordination reforms actually achieve superior policy outcomes.

\section{Acknowledgments}

We thank Robbert Biesbroek, Thomas Bolognesi, Guillermo Cejudo, Robert Duffy, Thurid Hustedt, Iris Meyer, three anonymous reviewers, and the editors of the journal for their comments and suggestions. We thank Stefano Assanti and Iris Meyer for their help with the data collection.

\section{Funding}

The authors acknowledge funding from the Swiss National Science Foundation, Grant/Award No. 162832. 


\section{Notes}

1. We use the Bayesian estimator built into the Stata (bayesmh), which is based on the Metropolis-Hastings sampling algorithm. The models are based on a Poisson distribution and assume uniform priors.

2. The figures are based on Bischof 2017.

3. Part 2 of the Supporting Information contains the fit statistics for the Bayesian models. The numbering of the models corresponds to the numbering of the models in part 1 of the Supporting Information, tables S3, S4, and S5.

4. The credibility intervals vary for the different estimates (see table $\mathbf{S 4}$ ). We show the change point in normal font if the credibility interval is lower than 10 years and in brackets if it is higher than 10 years.

5. The credibility intervals vary for the different estimates (see table S5). We show the change point in normal font if the credibility interval is lower than 10 years and in brackets if it is higher than 10 years.

\section{References}

Abbott, Kenneth W., and Duncan Snidal. 2009. The Governance Triangle: Regulatory Standards Institutions and the Shadow of the State. In The Politics of Global Regulation, edited by Walter Mattli and Ngaire Woods, 44-88. Princeton, NJ: Princeton University Press.

Adelle, Camilla, and Duncan Russel. 2013. Climate Policy Integration: A Case of déjà vu? Environmental Policy and Governance 23(1): 1-12.

Andrews, Rhys, Philippe Bezes, Gerhard Hammerschmid, and Steven Van de Walle. 2016. Conclusion: A Kaleidoscope of Administrative Reforms in Europe. In Public Administration Reforms in Europe: The View from the Top, edited by Gerhard Hammerschmid, Steven Van de Walle, Rhys Andrews, and Philippe Bezes, 273-80. Edward Elgar: Cheltenham.

Aurich-Beerheide, Patrizia, Serida L. Catalano, Paolo R. Graziano, and Katharina Zimmermann. 2015. Stakeholder Participation and Policy Integration in Local Social and Employment Policies: Germany and Italy Compared. Journal of European Social Policy 25(4): 379-92.

Bischof, Daniel. 2017. "New Graphic Schemes for Stata: plotplain and plottig." Stata Journal 17(3): 748-59.

Bogdanor, Vernor, ed. 2005. Joined-Up Government. New York: Oxford University Press.

Bouckaert, Geert, B. Guy Peters, and Koen Verhoest. 2010. The Coordination of Public Sector Organizations: Shifting Coalitions of Public Management. Basingstoke: Palgrave Macmillan.

Braun, Dietmar. 2008. Organising the Political Coordination of Knowledge and Innovation Policies. Science and Public Policy 35(4): 227-39.

Buchanan, David, and Richard Badham. 2008. Power, Politics, and Organizational Change: Winning the Turf Game, 2nd ed. London: Sage Publications.

Candel, Jeroen J.L., and Robbert Biesbroek. 2016. Toward a Processual Understanding of Policy Integration. Policy Sciences 49(3): 211-31.

Carlin, Bradley P., Alan E. Gelfand, and Adrian F. M. Smith. 1992. Hierarchical Bayesian Analysis of Changepoint Problems. Journal of the Royal Statistical Society Series C (Applied Statistics) 41(2): 389-405.

Champion, Cyrielle, and Guiliano Bonoli. 2011. Institutional Fragmentation and Coordination Initiatives in Western European Welfare States. Journal of European Social Policy 21(4): 323-34.

Christensen, Tom, Ole Martin Lægreid, and Per Lægreid. 2019. Administrative Coordination Capacity: Does the Wickedness of Policy Areas Matter? Policy and Society 38(2): 237-54.

Christensen, Tom, and Per Lægreid. 2007a. Introduction—Theoretical Approach and Research Questions. In Transcending New Public Management: The Transformation of Public Sector Reforms, edited by Tom Christensen and Per Lægreid, 1-16. Aldershot: Ashgate.

Christensen, Tom, and Per Lægreid, eds. 2007b. Transcending New Public Management: the Transformation of Public Sector Reforms. Aldershot: Ashgate.
Christensen, Tom, and Per Lægreid. 2007c. The Whole-of-Government Approach to Public Sector Reform. Public Administration Review 67(6): 1059-1066.

Christensen, Tom, Amund Lie, and Per Lægreid. 2007. Still Fragmented Government or Reassertion of the Centre. In Transcending New Public Management: The Transformation of Public Sector Reforms, edited by Tom Christensen and Per Lægreid, 17-41. Ashgate: Aldershot.

Dahlström, Carl, B. Guy Peters, and Jon Pierre. 2011. Steering from the Centre: Strengthening Political Control in Western Democracies. In Steering from the Centre: Strengthening Political Control in Western Democracies, edited by Carl Dahlström, B. Guy Peters, and Jon Pierre, 3-21. Toronto: University of Toronto Press.

Egeberg, Morten, and Jarle Trondal. 2016. Why Strong Coordination at One Level of Government Is Incompatible with Strong Coordination across Levels (And How to Live with It): The Case of the European Union. Public Administration 94(3): 579-92.

- 2018. An Organizational Approach to Public Governance: Understanding and Design. Oxford: Oxford University Press.

Entzinger, Han, and Renske Laura Biezeveld. 2003. Benchmarking in Immigrant Integration. European Research Centre on Migration and Ethnic Relations (ERCOMER), Erasmus University Rotterdam. https://ec.europa.eu/home-affairs/ sites/homeaffairs/files/e-library/documents/policies/legal-migration/pdf/general/ benchmarking_final_en.pdf [accessed October 28, 2019].

Eshbaugh-Soha, Matthew. 2006. The Conditioning Effects of Policy Salience and Complexity on American Political Institutions. Policy Studies Journal 34(2): 223-43.

Gelman, Andrew. 2008. Scaling Regression Inputs by Dividing by Two Standard Deviations. Statistics in Medicine 27(15): 2865-73.

Gerring, John. 2012. Mere Description. British Journal of Political Science 42(4): $721-46$.

Gormley, William T., Jr. 1983. Policy, Politics, and Public Utility Regulation. American Journal of Political Science 27(1): 86-105.

Hall, Peter. 1993. Policy Paradigms, Social Learning, and the State. The Case of Economic Policymaking in Britain. Comparative Politics 3(25): 275-96.

Head, Brian W., and John Alford. 2015. Wicked Problems: Implications for Public Policy and Management. Administration \& Society 47(6): 711-39.

Hood, Christopher. 1991. A Public Management for All Seasons? Public Administration 69(1): 3-19.

- 1995. The "New Public Management" in the 1980s: Variations on a Theme. Accounting, Organizations and Society 20(2-3): 93-109.

Hooghe, Liesbet, and Gary Marks. 2001. Types of Multi-Level Governance. European Integration Online Papers (EIoP) 5(11). http://eiop.or.at/eiop/pdf/2001-011.pdf [accessed October 28, 2019].

- 2003. Unraveling the Central State, but How? Types of Multi-Level Governance. American Political Science Review 97(2): 233-43.

Hou, Yilin, and Gene A. Brewer. 2010. Substitution and Supplementation between Co-functional Policy Instruments: Evidence from State Budget Stabilization Practices. Public Administration Review 70(6): 914-24.

Howlett, Michael, and Benjamin Cashore. 2009. The Dependent Variable Problem in the Study of Policy Change: Understanding Policy Change as a Methodological Problem. Journal of Comparative Policy Analysis: Research and Practice 11(1): 33-46.

Jain, Ritika, and Shubhro Sarkar. 2018. An Empirical Analysis of Disinvestment Policy in India: Does Ideology Matter? Journal of Economic Policy Reform 22(4): 384-98.

Jeannot, Gilles, and Philippe Bezes. 2016. Mapping the Use of Public Management Tools in European Public Administration. In Public Administration Reforms in Europe: The View from the Top, edited by Gerhard Hammerschmid, Steven Van de Walle, Andrew Rhys, and Philippe Bezes, 219-30. Cheltenham: Edward Elgar. 
Jochim, Ashley E., and Peter J. May. 2010. Beyond Subsystems: Policy Regimes and Governance. Policy Studies Journal 38(2): 303-26.

Jordan, Andrew, and Andrea Lenschow. 2010. Environmental Policy Integration: A State of the Art Review. Environmental Policy and Governance 20(3): 147-58.

Jordan, Andrew, and Adriaan Schout. 2006. The Coordination of the European Union. Oxford: Oxford University Press.

Jordana, Jacint, and David Levi-Faur. 2004. The Politics of Regulation: Institutions and Regulatory Reforms for the Age of Governance. Cheltenham: Edward Elgar.

King, Gary. 1986. How Not to Lie with Statistics: Avoiding Common Mistakes in Quantitative Political Science. American Journal of Political Science 30(3): 666-87. Klok, Pieter-Jan, Bas Denters, Marcel Boogers, and Maurits Sanders. 2018. Intermunicipal Cooperation in the Netherlands: The Costs and the Effectiveness of Polycentric Regional Governance. Public Administration Review 78(4): 527-36.

Krause, Rachel M., Christopher V. Hawkins, Angela Y. S. Park, and Richard C. Feiock. 2019. Drivers of Policy Instrument Selection for Environmental Management by Local Governments. Public Administration Review 79(4): 477-87.

Leemann, Lucas. 2015. Political Conflict and Direct Democracy: Explaining Initiative Use 1920-2011. Swiss Political Science Review 21(4): 596-616.

Levi-Faur, David. 2011. Regulatory Networks and Regulatory Agencification: Towards a Single European Regulatory Space. Journal of European Public Policy 18(6): 810-29.

Maggetti, Martino, and Fabrizio Gilardi. 2016. Problems (and Solutions) in the Measurement of Policy Diffusion Mechanisms. Journal of Public Policy 36(1): 87-107.

Maggetti, Martino, and Koen Verhoest. 2014. Unexplored Aspects of Bureaucratic Autonomy: A State of the Field and Ways Forward. International Review of Administrative Sciences 80(2): 239-56.

Mahoney, James, and Dietrich Rueschemeyer. 2003. Comparative Historical Analysis in the Social Sciences. Cambridge: Cambridge University Press.

McLaughlin, Kate, Stephen P. Osborne, and Ewan Ferlie. 2002. New Public Management: Current Trends and Future Prospects. London: Routledge.

Metcalfe, Les. 1994. International Policy Co-ordination and Public Management Reform. International Review of Administrative Sciences 60(2): 271-90.

Meyer, John W., and Brian Rowan. 1977. Institutionalized Organizations: Formal Structure as Myth and Ceremony. American Journal of Sociology 83(2): 340-63.

Ongaro, Edoardo. 2009. Public Management Reform and Modernization: Trajectories of Administrative Change in Italy, France, Greece, Portugal and Spain. Cheltenham: Edward Elgar.

Oreskes, Naomi, and Erik M. Conway. 2010. Merchants of Doubt: How a Handful of Scientists Obscured the Truth on Issue from Tobacco Smoke to Global Warming. London: Bloomsbury Press.

Painter, Martin, and B. Guy Peters. 2010. Administrative Traditions in Comparative Perspective: Families Groups and Hybrids. In Tradition and Public Administration, edited by Martin Painter and B. Guy Peters, 19-30. New York: Palgrave Macmillan.

Perri 6. 2004. Joined-Up Government in the Western World in Comparative Perspective: A Preliminary Literature Review and Exploration. Journal of Public Administration Research and Theory 14(1): 103-38.

Perri 6, Diana Leat, Kimberley Setzler, and Gerry Stoker. 2002. Towards Holistic Governance: The New Reform Agenda. Basingstoke: Palgrave Macmillan.

Peters, B. Guy. 2015. Pursuing Horizontal Management: The Politics of Public Sector Coordination. Lawrence: University Press of Kansas.

Peters, B.Guy. 2017. What Is So Wicked about Wicked Problems? A Conceptual Analysis and a Research Program. Policy and Society 36(3): 385-96.

Peters, B. Guy, and Donald J. Savoie. 1996. Managing Incoherence: The
Coordination and Empowerment Conundrum. Public Administration Review 56(3): 281-90.

Piattoni, Simona. 2010. The Theory of Multi-Level Governance: Conceptual, Empirical, and Normative Challenges. Oxford: Oxford University Press.

Pierson, Paul. 1998. Irresistible Forces, Immovable Objects: Post-Industrial Welfare States Confront Permanent Austerity. Journal of European Public Policy 5(4): 539-60. - 2000. Increasing Returns, Path Dependence, and the Study of Politics. American Political Science Review 94(2): 251-67.

Pollitt, Christopher, and Geert Bouckaert. 2017. Public Management Reform: A Comparative Analysis — Into the Age of Austerity. Oxford: Oxford University Press.

Prorok, Alyssa K., and Paul K. Huth. 2015. International Law and the Consolidation of Peace Following Territorial Changes. Journal of Politics 77(1): 161-74.

Reiter, Renate, and Tanja Klenk. 2018. The Manifold Meanings of "Post-New Public Management"-A Systematic Literature Review. International Review of Administrative Sciences 85(1): 11-27.

Rhodes, R. A. W. 1994. The Hollowing Out of the State: The Changing Nature of the Public Service in Britain. Political Quarterly 65(2): 138-51.

Richards, David, and Dennis Kavanagh. 2000. Can Joined-Up Government Be a Reality? A Case Study of the British Labour Government 1997-2000. Paper presented at the Australian Political Studies Association Conference, October 4-6.

Sarapuu, Külli, Per Lægreid, Tiina Randma-Liiv, and Lise H. Rykkja. 2014. Lessons Learned and Policy Implications. In Organizing for Coordination in the Public Sector, edited by Per Lægreid, Külli Sarapuu, Tiina Randma-Liiv and Lise H. Rykkja, 263-77. Basingstoke: Palgrave Macmillan.

Sartori, Giovanni. 1970. Concept Misformation in Comparative Politics. American Political Science Review 64(4): 1033-53.

Schaffrin, André, Sebastian Sewerin, and Sibylle Seubert. 2015. Toward a Comparative Measure of Climate Policy Output. Policy Studies Journal 43(2): 257-82.

Scholten, Peter, Elizabeth Collett, and Milica Petrovic. 2017. Mainstreaming Migrant Integration? A Critical Analysis of a New Trend in Integration Governance. International Review of Administrative Sciences 83(2): 283-302.

Slaughter, Anne-Marie. 2004. Disaggregated Sovereignty: Towards the Public Accountability of Global Government Networks. Government and Opposition 39(2): 159-90.

Song, Minsun, Hyung Jun Park, and Kyujin Jung. 2018. Do Political Similarities Facilitate Interlocal Collaboration? Public Administration Review 78(2): 261-69.

Streeck, Wolfgang, and Kathleen Thelen, eds. 2005. Beyond Continuity: Institutional Change in Advanced Political Economies. New York: Oxford University Press.

Tosun, Jale, and Achim Lang. 2017. Policy Integration: Mapping the Different Concepts. Policy Studies 38(6): 553-70.

Trein, Philipp. 2017a. Coevolution of Policy Sectors: A Comparative Analysis of Healthcare and Public Health. Public Administration 95(3): 744-58.

- 2017b. A New Way to Compare Horizontal Connections of Policy Sectors: "Coupling" of Actors, Institutions and Policies. Journal of Comparative Policy Analysis: Research and Practice 19(5): 419-34.

- 2018. Healthy or Sick? Coevolution of Health Care and Public Health in a Comparative Perspective. Cambridge: Cambridge University Press.

Trein, Philipp, Iris Meyer, and Martino Maggetti. 2019. The Integration and Coordination of Public Policies: A Systematic Comparative Review. Journal of Comparative Policy Analysis: Research and Practice 21(4): 332-49.

Zürn, Michael. 2000. Democratic Governance beyond the Nation-State: The EU and Other International Institutions. European Journal of International Relations 6(2): 183-221.

\section{Supporting Information}

Supplementary appendices may be found in the online version of this article at http://onlinelibrary.wiley.com/doi/10.1111/puar.13117/full 